\title{
ESPECIALISTAS ADVERTEM: O PAI É IMPORTANTE PARA O DESENVOLVIMENTO INFANTIL
}

Inês Hennigen ${ }^{\star}$

\begin{abstract}
Resumo
Discuto resultados de pesquisa que buscou conhecer os discursos da mídia sobre paternidade e seus efeitos nos modos de subjetivação. Aqui abordo um dos enunciados identificados: a criança é um ser em desenvolvimento e por isto precisa de seu pai. Focalizo quatro aspectos: a importância da noção de desenvolvimento para a codificação da infância e o controle social de crianças e adultos; a forma como as posições de pais e mães foram sendo construídas como lugares distintos e hierarquicamente díspares; as transformações nas posições sociais de crianças e pais; a crescente primazia do saber/poder dos especialistas frente ao saber parental.

Palavras-chave: discurso; infância; paternidade; gênero; especialistas.
\end{abstract}

\section{EXPERTS WARN: THE FATHER IS IMPORTANT FOR THE INFANTILE DEVELOPMENT}

\begin{abstract}
I discuss the results from the research that sought to know the media discourses on paternity and its effects on subjectivation ways. Here I approach one of the identified statements: the child is a person in development and therefore needs his father. I focus in four aspects: the importance of the concept of development for the codification of childhood and children and adult's social control; the way the fathers and mothers positions were being constructed as distinct and hierarchically unlike places; the changes in the status of children and parents; the growing primacy of knowledge/power of experts opposing parental knowledge.
\end{abstract}

Keyword: discourse; childhood; paternity; gender; experts.

\footnotetext{
^ Professora do Departamento de Psicologia Social e Institucional do Instituto de Psicologia da Universidade Federal do Rio Grande do Sul e docente do PPG em Psicologia Social e Institucional da UFRGS. Endereço: Instituto de Psicologia da UFRGS - Rua Ramiro Barcelos, 2600, sala 311, CEP 90035-003, Porto Alegre/RS.

E-mail: ineshennigen@gmail.com.
} 
O recurso a uma paródia das mensagens inscritas nos maços de cigarro para compor o título tem como objetivo mostrar que, cada vez mais, nossas ações têm sido reguladas por instâncias consideradas autoridades no bem-viver. Aqui faço referência à chamada expertise da subjetividade (ROSE, 1998; SILVA, 1998): profissionais de vários campos que tem arvorado sua capacidade de compreender e orientar as pessoas acerca dos aspectos psicológicos. Neste cenário, muito conhecimento sobre a infância tem sido produzido. Saberes que, em uma perspectiva foucaultiana, não revelam uma realidade pré-existente acerca da mesma, mas contribuem para sua produção.

As discussões que apresento aqui têm como base minha pesquisa de Doutorado (HENNIGEN, 2004), onde busquei conhecer os discursos que a mídia contemporânea produz e faz circular sobre a paternidade, e refletir acerca dos modos de subjetivação engendrados como efeitos de tal rede discursiva. Na análise dos discursos (FOUCAULT, 1999; 2000a), identifiquei uma série de enunciados ${ }^{1}$ que remetem a diversas concepções (família, masculinidade, infância, entre outras) que se conjugam nos discursos sobre a paternidade.

Neste artigo multiplico - no sentido foucaultiano de colocar em relação - um dos enunciados identificados na análise desses discursos, a saber: a criança é um ser em desenvolvimento e por isto precisa de seu pai. Importante esclarecer que um enunciado encontra-se na transversalidade das frases, das proposições e dos atos de linguagem (FOUCAULT, 2000a). Portanto, sua codificação em palavras é um exercício de criação. Apesar do enunciado apresentado acima ser próximo a frases encontradas nos materiais analisados, esta correspondência não é importante. O fundamental, nesse tipo de análise, é atentar para as múltiplas relações em torno do que está sendo dito, do que se enuncia.

Assim, ao abordar o enunciado em questão, discuto suas condições de emergência e desdobramentos, realçando seu caráter histórico. Isso possibilita questionar as significações que foram se tornando hegemônicas, desnaturalizálas e mostrar que são fruto de estratégias que buscam fixá-las e que respondem a objetivos de governo. Por outro lado, é importante ressaltar que tal produção discursiva institui lugares, produz identidades, contribui para a regulação social. Por isto, também problematizo os lugares daqueles que estão ligados às crianças: pais, mães e, de forma crescente, os especialistas em infância.

Na pesquisa a que referi acima (HENNIGEN, 2004), analisei vários produtos midiáticos ${ }^{2}$ neste artigo, para tecer as discussões, lanço mão de parte desse material: uma cena da novela Mulheres Apaixonadas (2003), produzida e veiculada pela Rede Globo, que teve como uma das tramas a história de Heloísa, mulher obcecada pelo marido, que não queria ter filhos para não ter de dividi-lo com alguém; ${ }^{3}$ a reportagem "É tão importante como a mãe", do jornal gaúcho Correio do Povo, publicada em doze de agosto de 2001 (Dia dos Pais); e o comercial de televisão das Lojas Renner, que integrava a campanha publicitária desta rede de lojas para o Dia dos Pais de 2000, veiculado em vários canais de televisão na quinzena anterior a essa data. 
Inicio a discussão das relações que atravessam o enunciado em foco abordando algumas condições que possibilitaram o surgimento da categoria infância. Mostro que a concepção de criança como um ser em desenvolvimento abriu espaço para empreendimentos escolares que visavam o controle e a regulação social, objetivos potencializados por saberes científicos, em especial os produzidos no campo Psi. Posteriormente, focalizo os conhecimentos construídos pelas disciplinas Psi acerca do que se costuma chamar papel do pai no desenvolvimento infantil. E, como toda construção identitária posiciona socialmente os sujeitos e implica relações de poder, problematizo os lugares atribuídos a pais e mães neste processo a luz das perspectivas feministas e de gênero. Na terceira parte deste escrito abordo as transformações nas posições de pais e de crianças na contemporaneidade. Esta discussão traz a tona o último tópico de reflexão: a crescente importância - em termos de regulação e controle das vivências subjetivas - que os especialistas têm adquirido em nossa sociedade.

\section{A COnStruÇão da nOÇão de CRIAnÇA COMO UM SER EM DESENVOLVIMENTO}

A codificação da infância constitui fato relativamente recente; crianças sempre existiram, mas a descrição dos cuidados para com elas, a elaboração de critérios para avaliar seu desenvolvimento e a instituição de operações para garantir sua transformação em cidadãos aconteceu na Modernidade. Na época, a sociedade européia ocidental encontrou a alteridade: os povos primitivos e as crianças. A atitude política em relação a estes dois "outros" foi idêntica: conquistar e dominar. Ambos eram vistos, paradoxalmente, como o bem e o mal, o inocente e o pecador e deveriam ser educados até chegar à idade da razão (BARBOSA, 2000). A noção de evolução, que permitia ordenamento lógico e teleológico, foi aplicada na compreensão de indivíduos e da sociedade: ambos passariam de estágios mais simples (crianças/primitivos) para mais complexos (adultos/civilizados). Neste sentido, Castro (1998) diz que o novo estatuto das crianças na sociedade moderna foi possível a partir da entronização da idéia de desenvolvimento.

A noção moderna de infância forjou-se quando, distanciada das vivências adultas, a criança foi adquirindo espaço e valor próprios. Gélis (1991) mostra que o início da sua valorização não aconteceu no âmbito das expressões de afeto, mas pela vontade de preserva-lhe a vida, desejo crescente no século XVI e ligado à idéia, também nascente, de perpetuação através dos filhos - mutação cultural gradativa que se disseminou de forma não linear nos diferentes espaços sociais.

Ariès (1981), referência clássica sobre infância, refere-se a dois sentimentos que foram aparecendo em relação às crianças: a paparicação, que surgiu do convívio de adultos e crianças no meio familiar (elas, por sua graça e ingenuidade, encantavam e alegravam os adultos) e a preocupação com a racionalidade dos costumes e com a disciplina, que proveio de fontes externas à família, como eclesiásticos, juristas e moralistas.

Duas visões de infância, ambas fomentadas pela Igreja, coexistiam: a criança concebida como rude e fraca de juízo, com a alma marcada pelo mal (propensa ao pecado), que devia ser vigiada e disciplinada; e o infante associado a elemen- 
tos de pureza (criatura de Deus), ingenuidade, maleabilidade e fragilidade, que deveria ser preservado. Contudo, independente da visão, a educação das crianças era apontada como uma necessidade. Assim, toda uma maquinaria escolar passou a ser construída para discipliná-las, governá-las (BARBOSA, 2000).

A escola, junto à família, ${ }^{4}$ foi a instituição que se encarregou de proteger, disciplinar, educar e civilizar a criança. Com base em um ideal a ser atingido, a escola instituiu uma seqüência de procedimentos e etapas para que a criança pudesse desenvolver-se e alcançar tal ideal. O tempo da infância tornou-se uma negação de sua condição presente, pois se tratava de um tempo a ser superado (CASTRO, 1998).

As crianças, então, passaram a ser alvo de operações que administravam seus corpos e visavam a gestão da sua vida. Foram inseridas, junto a suas famílias, em processos de controle e regulação sofisticados, porque invisíveis e consentidos, e produtivos, pois engendravam modos de ser. Isto impulsionou a definição de espaços próprios para a educação das crianças e o surgimento de práticas de educação de pais e mães, que tinham suas ações prescritas em uma série de tratados moralistas.

Corpos e mentes infantis (a partir daí, sem cessar) passaram a ser esquadrinhados pelas ciências - em especial pela Pedagogia, Psicologia e Medicina Higienista -, num duplo movimento de descrição e indicação desta descrição como a forma segundo a qual as crianças deveriam ter seu desenvolvimento observado. Desta maneira, produziam aqueles que diziam (só) descrever. ${ }^{5}$ Assim, a produção de saberes passou a regular as condutas - infantis e de adultos - num jogo de poder contínuo e minucioso que atravessava o corpo social.

Até nossos dias, é difícil desemaranhar a compreensão da infância da noção de desenvolvimento, que foi, neste sentido, naturalizada neste processo de produção histórica. Parece natural e óbvia a crença em que a criança é, mais do que qualquer sujeito, um "ser em desenvolvimento". Mais ainda, a noção de desenvolvimento tomou o cunho de um ideário ético onde se alia desenvolvimento e normalidade psicológica, desenvolvimento e saúde mental. Portanto, a noção de desenvolvimento na Psicologia prevê e determina o próprio desenrolar da vida infantil. (CASTRO, 1998, p. 7)

\section{O PAI E O DESENVOLVIMENTO INFANTIL: CRÍTICAS À HIERARQUIA DE GÊNERO}

De acordo com Ariès (1981), na época pré-moderna, os filhos tinham lugar na família não em função de um sentimento existencial, mas pela contribuição que ofereciam à instituição familiar: eles representavam uma vantagem econômica.

Hoje, nos países ocidentais, um filho, ao contrário, representa um grande encargo financeiro para os pais. A decisão de ter um filho é muito mais definida e específica do que costumava ser, e é guiada por necessidades psicológicas e emocionais. 
Os temores acerca do efeito do divórcio sobre os filhos e da existência de muitas famílias sem pai têm de ser compreendidas contra o pano de fundo das expectativas muito mais elevadas que temos com relação ao modo como as crianças deveriam ser cuidadas e protegidas. (GIDDENS, 2000, p. 69-70)

A partir do cenário familiar contemporâneo oferecido por Giddens (2000), se pode compreender a posição apresentada em alguns materiais midiáticos e que será discutida na seqüência: filhos são tomados naturalmente como a razão de viver de pais e mães e eles necessitam, para um desenvolvimento pleno, ter o pai próximo. Tal posição pode ser encontrada tanto em narrativas midiáticas ficcionais quanto em matérias jornalísticas. Para melhor explorar a questão, a seguir apresento uma cena da novela Mulheres Apaixonadas (com transcrição literal do áudio) e cito excertos da reportagem "É tão importante como a mãe" (2001).

Trata-se de uma cena da novela Mulheres Apaixonadas (2003) em que a personagem Heloísa, que está no hospital após um acidente, puxa conversa com uma atendente sobre casamento (sua grande preocupação) e filhos:

Heloísa: E o seu [casamento] já começou a balançar?

Atendente: Bom, por enquanto, graças a Deus, está tudo bem...

Heloísa: Mas você tem filhos...

Atendente: Um casal. Razão da minha vida, do meu trabalho. E do meu marido também. Que ele como pai, nossa, é o melhor do mundo. Muito melhor pai do que marido. Mas eu prefiro assim. As crianças precisam mais dele do que eu. (MULHERES..., 2003)

O acento sobre a necessidade "de pai” das crianças também fica explicitada na matéria "É tão importante como a mãe", onde se lê:

A presença paterna é tão fundamental quanto a materna para a construção da identidade da criança. Segundo Ricardo Becker Feijó, professor doutor de Pediatria da Faculdade de Medicina da Ufrgs, a influência do pai é importantíssima para o desenvolvimento do filho. ... Feijó orienta também que o pai divida as funções com a mãe. "Eles devem compartilhar ao máximo o cuidado com o nenê, como o banho e a troca de fraldas e não só na hora da recreação", afirma. ... Adriana Wagner, professora doutora da Faculdade de Psicologia da PUC, concorda que a presença do pai é necessária à criança. "O filho precisa da figura paterna para sua segurança. O pai é quem faz a construção para a barreira externa, é o último não", afirma (É TÃO..., 2001, p. 8). 
As disciplinas Psi, além da Medicina e outras, encarregaram-se, no último século, de dar visibilidade à criança, "descrevendo" suas habilidades e comportamentos, as etapas de seu desenvolvimento e as posições que pais e mães precisam assumir para o sucesso do mesmo. Assim, produziram saberes e, correlativamente, ajudando na constituição de modos ("corretos", "normais") de ser criança, mãe, pai. Seus "representantes" passaram a ser reconhecidos socialmente como autoridades para falar sobre as crianças: as expressões doutor/a, usadas na matéria jornalística, parecem servir para indicar o valor do que está sendo dito. Deste modo, forneceram parâmetros para sua educação e para intervenções de variados profissionais (assistentes sociais, juízes, enfermeiros, professores, entre outros). Portanto, os saberes forjados no campo Psi e outros se somaram às iniciativas do sistema escolar para a regulação dos infantes e de seus cuidadores, potencializando o controle social.

A noção de desenvolvimento passou a ser tão importante no campo Psi que certas abordagens fizeram uma torção no conceito freudiano de complexo de Edipo para teorizar o lugar do pai em sintonia com essa noção, dando ênfase à presença dele junto ao filho. ${ }^{6}$ Nessa direção, Aberastury e Salas (1991, p. 76) afirmam que "a carência de contato com o pai, sobretudo de um contato corporal cotidiano com ele, deixa um déficit que se encontra logo na base do desejo pelo pai".

O recorte da produção desta perspectiva psicanalítica pós-freudiana aponta uma tendência funcionalista, adaptacionista e normatizadora que irá se consolidar na psicologia com a focalização das ações reais do pai. Ele passa a ser referido como um motor do desenvolvimento a partir de sua ação efetiva junto à criança, principalmente em relação às questões de moralidade e identidade sexual. Neste contexto, uma série de estudos (MUZIO, 1998; SILVEIRA, 1998) passa a enfatizar os efeitos nocivos de sua ausência ou de falhas no desempenho de seu papel, o que deixaria os filhos suscetíveis a toda ordem de transtornos. E a expertise não cansa de afirmar tais saberes: na matéria do jornal, tanto a necessidade de contato corporal (banho e fraldas) como a moralidade (o último não) são indicações bem precisas de como deve agir um pai.

Por outro lado, a gradativa construção do que se poderia chamar de identidade do pai foi se alicerçando nas diferenças de gênero - e, reciprocamente, ajudando a produzi-las. Assim, pais e mães foram sendo posicionados socialmente em pólos distintos, estanques e hierarquicamente díspares.

Costa (1997), por exemplo, concebe a posição adequada do pai a partir de três funções: proteger a mãe durante a gestação e início da vida do filho; ajudar o filho a separar-se da mãe (evitando a continuidade da relação narcísica e indiferenciada estabelecida após o nascimento); e, por fim, ajudar a criança a perceber as diferenças intergeracionais e entre as figuras parentais, oferecendo-se como modelo de identificação para o filho e de companheiro para a filha. "Na mesma medida em que a mãe é a propiciadora do nascimento biológico do filho, complementarmente é o pai que cria as condições necessárias para o seu nascimento psicológico" (COSTA, 1997, p. 15). 
Para Foucault (2000a), os discursos, em si, não são falsos nem verdadeiros, pois são os próprios discursos que estabelecem regimes de verdade, que definem e separam o verdadeiro do que não é verdadeiro (para certa inteligibilidade). Dentro de cada discurso são os enunciados que sinalizam o que é tomado como verdade em um tempo e espaço determinado. Em função disso, cabe a pergunta: é apropriado ou não questionar os discursos que as disciplinas Psi têm produzido acerca do tema?

Penso que fazer tal questionamento, além de pertinente, é fundamental. Os regimes de verdade, no jogo social de lutas, buscam impor seus significados, estabelecer certos modos de compreensão do mundo. A perspectiva foucaultiana ensina a desconfiar das "verdades naturalizadas" e buscar os jogos de poder que perpassam o corpo social. Uma vez que as pessoas subjetivam-se a partir dos discursos (isto é, tomam o que é dito como verdades para si e sobre si), é fundamental problematizá-los, desnaturalizá-los para que outros modos de ver o mundo - e ser no mundo - possam ser engendrados.

Os saberes construídos no campo Psi, como o escrito de Costa (1997), apresentado acima, marcam nitidamente uma polarização e hierarquização entre as posições de pai e mãe. Essas remetem às representações masculinas e femininas hegemônicas e estão ancoradas nas dicotomias razão/emoção e cultura/natureza. Recapitulando o que esse autor diz: cabe ao pai "dar apoio" e proteção à mãe, "ajudar" o filho na busca do mundo "externo", "separar" mãe e filho (logo, ser racional frente a tanta emoção) e viabilizar o nascimento "psicológico"; correlativamente, a mãe estabelece uma relação fusionada com o filho e viabiliza seu nascimento "biológico". Uma vez que aquele que recebe apoio e ajuda está numa situação de inferioridade, e que o nascimento biológico passa a ter sentido quando se instala o psicológico, pode-se concluir que o pai ocupa uma posição de maior "poder" na dupla parental.

Os estudos feministas e de gênero vêm questionando os lugares de homens e mulheres na sociedade e buscam mostrar que não se tratam de condições dadas pela natureza, mas de construções culturais que respondem a disputas por espaços: rebatidas sobre as relações de gênero estão as relações de poder. A partir desta compreensão, esses estudos passaram a problematizar o espaço doméstico e os cuidados das crianças. Ações políticas e produções teóricas foram feitas para superar as desigualdades nas relações familiares. Neste sentido, Ramires (1997) propôs que, se os cuidados infantis fossem compartilhados desde o início por homens e mulheres, as crianças aprenderiam um novo modelo de relação, não mais hierárquico, excludente e de poder, mas sim de cooperação e complementação. ${ }^{7}$ Este ideário tem atravessado a fala dos especialistas em infância, como mostram os fragmentos da matéria do jornal apresentados anteriormente.

Entretanto, essas abordagens foram questionadas dentro do próprio campo dos estudos feministas por despolitizar as desigualdades. A privatização das diferenças de gênero foi criticada, pois, uma vez remetidas ao âmbito doméstico 
(o tipo de relação ali estabelecida seria sua origem; alterando-o, o equilíbrio de gênero seria alcançado), as dimensões históricas, sociais, políticas, econômicas das mesmas ficavam invisibilizadas.

Contudo, a insistência com que o discurso feminista convocou os homens a assumir uma posição ativa junto aos filhos, somada às indicações das teorias Psi sobre o papel do pai no desenvolvimento das crianças, gerou repercussões. Tal idéia atravessou o tecido social e, por isto, não surpreende que ao final do comercial que é apresentado e analisado a seguir diga-se que o compromisso mais importante de um homem é ser pai.

\section{Posições QUe SE ALTERAM: o NOVO LUGAR dAS CRIANÇAS E DOS PAIS}

O comercial das Lojas Renner para a campanha do Dia dos Pais de 2000 traz a seguinte situação: em um escritório, um homem é convocado pelo chefe para viajar no final de semana para uma reunião. Uma menina aparece por detrás dele e questiona o chefe, de forma reiterada, porque seu pai deve ir (a cada resposta, lança novo por que). O chefe, primeiro com firmeza, depois parecendo ter de justificar-se, diz, sucessivamente, que se trata de assunto muito importante, que é um grande negócio, que envolve o futuro de todos, que dele depende o crescimento [da empresa]. Então a menina fala: "E por acaso meu crescimento não depende do meu pai?" Esse, focado em segundo plano, disfarça o sorriso; o chefe também esboça um sorriso de canto de boca. Muda o cenário, pai e filha estão em um parque. Em off, se ouve a frase "nunca esqueça o seu compromisso mais importante: ser pai. Lojas Renner."

A análise dessa peça publicitária possibilita discutir a mobilidade das significações acerca das posições sociais dos pais e das crianças. Um primeiro aspecto diz respeito à tensão entre esfera pública (aqui, o mundo do trabalho) e privada (aqui, o espaço familiar).

À época da Revolução Industrial, família e trabalho dissociaram-se. Com o desenvolvimento do capitalismo, gradativamente o eixo da produção deslocou-se da unidade econômica familiar para as fábricas (PERROT, 1991b). Esse espaço, que integra a chamada esfera pública, passou a ser ocupado pelo homem, na casa permanecendo mulheres e crianças. Com o tempo, a ligação entre mundo do trabalho e masculinidade se solidificou. Tal associação seguiu forte até que, nas últimas décadas do século XX, face à entrada maciça das mulheres no mercado de trabalho e às lutas feministas, se demandou com mais vigor uma "recíproca" masculina: um maior vínculo dos homens com o espaço doméstico, uma posição mais ativa no cotidiano familiar e no cuidado dos filhos.

O comercial traz um impasse bem atual. Se, por um lado, o homem não questiona viajar a trabalho no final de semana, por outro, após a filha "convencer" seu chefe, eles aparecem se divertindo em um parque. Aqui é possível constatar a tensão entre significações colocadas em confronto, em disputa pela 
interpelação dos sujeitos, o que seguramente têm contribuído para a subjetivação dos homens na sociedade contemporânea: ter de trabalhar (inclusive nos finais de semana) e ter de ser um pai presente.

A posição do chefe também é interessante. No início ele demonstra segurança ao dizer que trata de um grande negócio, mas como a menina não aceita suas respostas, ele assume uma postura de quem se justifica. A criança "ganha" a discussão. Mesmo diante da seriedade do mundo dos negócios, parece que ela tem prioridade.

Este lugar privilegiado da criança foi sendo construído gradativamente desde o início da Modernidade. Corazza (2002), com humor e boa dose de crítica, conta a saga das crianças, que chama de gentes pequenas, e que foram se tornando visíveis, alvos de atenção, cuidado e controle por parte das gentes grandes - o adulto centrado, racional - a quem se refere genericamente como o "Indivíduo". Corazza (2002, p. 49) escreve: o Indivíduo "convocou então todas as grandes que fez existir para só se ocuparem das pequenas e elas se instalaram na escola, com aqueles discursos que o Indivíduo chamou 'ciências da educação' os quais 'descreviam' (?!) as gentes pequenas".

Assim, a criança se diferenciou e distanciou dos adultos, adquirindo um novo lugar social e familiar, justificando as intervenções do Estado e dos especialistas, e a prática da educação institucionalizada. Iniciou-se um movimento no sentido de preservar sua inocência (leia-se: instituí-la): era preciso amá-las e educá-las para que pudessem desfrutar período tão doce e cumprissem a promessa de um futuro brilhante.

Não estranha então que Freud (embora convencido de descrever um universal trans-histórico) nos dê esta explicação do amor moderno pelas crianças: as amamos como ectoplasmas de uma perfeição que os avatares da vida já nos recusaram. Delas, esperamos que nos ofereçam a imagem de uma plenitude e de uma felicidade que não é, e nunca foi, aliás, a nossa, mas graças à qual podemos amar a nós mesmos. Olhamos para elas como para uma foto de nossa infância onde queremos parecer felizes. E para isso as protegemos, cuidamos e satisfazemos (CALLIGARIS, 1996, p. 216).

Calligaris (1996) pondera que só amamos as crianças na medida em que elas encarnam o ideal de perfeição. No comercial, a menina é retratada de tal forma que é possível vislumbrar sua condição de "criança com futuro", logo, que tem o direito de ser amada, de ter o pai para si. Por outro lado, o pai literalmente não tem voz (não emite qualquer verbalização), somente acompanha a fala da filha e sorri mostrando júbilo quando ela deixa o chefe sem palavras. Apesar de a menina dizer que depende do pai, esse nada fez por ela. Fica a impressão que basta sua presença. 
A concepção de que o crescimento (ou desenvolvimento) de uma criança depende do posicionamento de seus pais e mães é um lugar-comum social. Já a referência à importância da participação "ativa" do pai na vida dos filhos pode ser considerada, como visto acima, um desdobramento de dois movimentos que se complementam: as lutas feministas que buscam um novo equilíbrio nas relações entre os gêneros e a crescente influência das teorias psicológicas e educativas junto às famílias.

\section{A guisa de FinalizaÇão: CRIANÇA É QUESTão PARA ESPECIALISTAS?}

É interessante atentar para o fato de que no comercial é dito, em off, que o compromisso mais importante de um homem é ser pai. Quem fala? Proponho que a voz é desta entidade "etérea" (mas bem real!) que se tem nomeado expertise da subjetividade. Na atualidade, parece que pais e mães realmente estão sem voz. Quem fala por eles são médicos, psicoterapeutas, especialistas em família, em nutrição, juristas, psicanalistas. É como se somente a partir da "verdade" que estas "autoridades" enunciam que pais e mães passam a saber algo sobre suas próprias crianças.

Para contextualizar tal guinada - a primazia do saber dos especialistas frente ao saber parental - cabe lembrar que no processo de construção da concepção moderna de infância, ao longo do século XIX, o pai teve suas prerrogativas cada vez mais restringidas. Em nome do "interesse da criança", o Estado começou a intervir no seio da família, chegando a se contrapor ao pai quando este era considerado negligente.

Contudo, para Knibiehler (1997), o declínio do poder do pai não significou um golpe no patriarcalismo. Isto porque o poder sobre criança e mãe deixou de ser paterno, mas passou a ser dos especialistas - homens que elaboravam as leis e estabeleciam normas de conduta e educação. "El patriarcado ya no funciona en el interior de la familia, pero conserva toda su potencia en la sociedad" (KNIBIEHLER, 1997, p.133).

No século XVI apareceram as primeiras disposições legais acerca da infância. Mesmo pouco aplicadas, Gélis (1991) vê nelas os primórdios da política de proteção à infância e da intervenção mais ampla do Estado nas questões demográficas. Diferentes dispositivos foram sendo criados para defender os interesses das crianças, se instituindo uma rede de saberes/poderes que autorizava alguns a falar em seu nome. Como o tempo, os discursos da Psicologia passaram a orientar o que era o melhor para a criança, atravessando inclusive as decisões jurídicas.

Ressalte-se que esta codificação da infância não funciona somente como diretriz para casos-limites, mas constitui uma face das estratégias de regulação e controle social. Os sujeitos passam a produzir seus modos de ser a partir destes regimes de verdade. Assim, quando ensinados a ser ou fazer algo, os sujeitos forjam-se imersos em relações de saber/poder. Não de um poder maiúsculo, mas 
de um poder que, deslizando entre as pessoas, instituições e práticas, vai lhes posicionando socialmente, numa constante luta interpelativa pela imposição de significados culturalmente produzidos.

A invenção da infância pela sociedade moderna engendrou-se a partir de uma ampla rede de saberes, que incluía os campos da Educação, Direito, Medicina e Psicologia. Como coloca Knibiehler (1997), a tecnologização da função parental é crescente. Desde a concepção, a vida da criança é controlada e regulada pelos mais variados especialistas em nome de sua saúde, bem-estar, interesse, proteção.

De fato, o filho não pertence apenas aos pais: ele é o futuro da nação e da raça, produtor, reprodutor, cidadão e soldado do amanhã. Entre ele e a família, principalmente quando esta é pobre e tida como incapaz, insinuam-se terceiros: filantropos, médicos, estadistas que pretendem protegê-lo, educá-lo, discipliná-lo[...]

Objeto de disputa de poderes, a infância também é lugar de saberes, que se desenvolvem sobretudo no último terço do século XIX, com o esforço conjunto da medicina, da psicologia e do direito. Estes saberes surtem efeitos contraditórios. Produtores de controle, também geram conhecimentos que convertem nossa infância num mistério insondável (PERROT, 1991a, p. 148).

A centralidade adquirida pelos especialistas em regulação da conduta humana em nossa sociedade tem deslocado e desqualificado outros saberes, como os parentais. Assim, como diz Costa (1999) em relação à ação dos pais e mães, existe sempre um "a mais a corrigir" ou um "a menos" a tratar. Educar as crianças parece ser sobre-humano: os especialistas estão aí a apontar os excessos e deficiências dos pais e mães. ${ }^{8}$

Neste ponto é pertinente lançar mão do conceito de governamentalidade (FOUCAULT, 2000b): ele refere-se às práticas de governo ou, mais especificamente, de governamento que têm na população seu objeto, na economia seu saber e nos dispositivos de segurança seus mecanismos básicos. Rose (1998) esclarece que a governamentalidade diz respeito ao conjunto de instituições, procedimentos, análises e reflexões, cálculos e táticas que permitem o exercício de uma forma complexa e específica de poder sobre a população. Este autor aponta a relação entre governamento e saberes sobre a subjetividade. Afirma que duas características do governo são importantes para compreender esta ligação: o governo depende do conhecimento (é preciso saber sobre características e processos próprios da população, desenvolvendo esquemas explicativos) e este deve ser de um tipo específico (é preciso traduzir os fenômenos em materiais sobre os quais o cálculo político possa trabalhar, isto é, traduzir em números, estatísticas).

O processo de governamentalização está, desta forma, vinculado ao papel dos experts na criação e administração das tecnologias da subjetividade. $\mathrm{O}$ processo de desestatização da governamentalidade e da governamentalização do 
Estado acontece no deslocamento de estratégias centralizadoras de regulação da conduta para estratégias colocadas sob a responsabilidade da expertise (Silva, 1998). O conhecimento e a expertise moderna da psique não operam somente no sentido de constrangimento ou repressão da liberdade do indivíduo. Ao contrário, estimulam a subjetividade promovendo auto-inspeção e autoconsciência, moldam desejos, buscam maximizar as capacidades intelectuais - buscam produzir indivíduos "livres para escolha".

O governo da alma depende de nos reconhecermos como, ideal e potencialmente, certo tipo de pessoa, do desconforto gerado por um julgamento normativo sobre a distância entre aquilo que somos e aquilo que podemos nos tornar e do incitamento oferecido para superar essa discrepância, desde que sigamos o conselho dos experts na administração do eu (ROSE, 1998, p. 44).

A invenção da infância, a mudança das relações entre adultos e crianças, aconteceu numa sociedade que se organizava sobre novas bases. A Modernidade, entre tantos outros aspectos, marcou a gradativa perda de potência do poder soberano e sua substituição por uma nova forma de governar. Se, em relação à infância, em um primeiro momento o foco incidiu sobre a educação das crianças para assegurar que elas se transformassem em adultos "civilizados", logo em seguida a atenção recaiu sobre as ações das mães, que passaram a ser vistas (e a se ver - face à eficácia do processo interpelativo) como responsáveis pelo desenvolvimento dos infantes. O pai, que no processo de construção da infância moderna perdeu grande parte das prerrogativas que o antigo poder paterno lhe outorgava (PERROT, 1991a), ${ }^{9}$ voltou ao cenário no século XX. Desta vez a importância que passou a ter não derivava de "seu" poder: o pai reconquistou prestígio pela ação dos especialistas em infância, que lhe atribuíram lugar (cada vez mais) significativo na vida de seus filhos. A princípio, a recomendação foi para que se fizessem presentes no cotidiano deles como lei e modelo. Uma vez que as separações e divórcios cresceram em nossa sociedade, os riscos da ausência paterna passaram a ser insistentemente apontados, e os especialistas começaram a disponibilizar maiores orientações sobre como todos deveriam proceder. Estavam postas as condições para o surgimento do "novo pai", aquele que, como diz o comercial, deve lembrar sempre que seu compromisso mais importante é ser pai.

Mas, o que é "ser pai"? Não podemos viver fora das redes discursivas de nosso tempo. Mas se problematizarmos os modos de ser que nos tem sido oferecidos pelos especialistas, talvez surjam brechas para que construções mais singulares possam advir. Quem sabe os homens, confrontados e confrontando os discursos que os mais diversos campos de saber produzem sobre a paternidade, possam ir inventando seus modos de ser pai - sem advertências (muito) severas. 


\section{Notas}

${ }^{1}$ São as coisas “ditas" em uma formação discursiva: um discurso qualquer, o discurso político, por exemplo, pode ser compreendido como um conjunto de enunciados apoiados numa determinada formação discursiva - no caso, a da ciência política -, que funciona como uma matriz de significados. Contudo, é importante considerar que os enunciados de qualquer formação estão sempre em correlação dinâmica com coisas ditas em outros campos (FISCHER, 1997).

${ }^{2}$ A novela Mulheres Apaixonadas, produzida e exibida pela Rede Globo em 2003; 16 comerciais de televisão veiculados na quinzena anterior ao Dia dos Pais de 2000; reportagens dos jornais gaúchos Correio do Povo e Zero Hora (entre 2001 e 2003) e da Revista Veja (2002), de circulação nacional, que abordaram a paternidade.

${ }^{3}$ Essa novela, escrita por Manoel Carlos, foi exibida entre 17 de fevereiro e 10 de outubro de 2003, tendo ao todo 203 capítulos.

${ }^{4} \mathrm{~A}$ nova educação fez com que as sociabilidades da comunidade e do parentesco extenso fossem deixadas de lado - as crianças passaram à privacidade do lar e ao seu complemento, o ambiente escolar.

${ }^{5}$ Cabe lembrar que Foucault (2000a) concebe discurso como uma prática que forja os objetos dos quais fala. Assim, descrever processos, acontecimentos ou traçar caracterizações, por exemplo, é também contribuir para a sua produção, pois todo campo de saber é perpassado por relações de poder e engendra modos de ser - remetidos aos regimes de verdade assim instaurados.

${ }^{6}$ Sobre as posições psicanalíticas acerca do complexo de Édipo e da função simbólica do pai, ver Dor (1991). A discussão lançada aqui está aprofundada em Hennigen (2007).

${ }^{7}$ Sintonizados com esses discursos, pesquisadores passaram a estudar o maior envolvimento do pai nos cuidados dos filhos, utilizando a expressão novo pai para designá-lo (ARILHA, MEDRADO, RIDENTI, 1998).

${ }^{8}$ Cabe assinalar que a maior parte das matérias dos jornais e revistas que constituíram os materiais empíricos da pesquisa traziam algum especialista informando como os pais ou o casal parental deveria agir nas mais variadas situações

${ }^{9}$ Perrot (1991a, p. 122) nos dá uma mostra de tal poder: “[...] o pai pode mandar prender os filhos e recorrer às prisões do Estado, como se fazia no sistema das ordens régias, a título de 'correção paterna’, o qual mantém uma polícia de família onde o poder público age por delegação”.

\section{REFERÊNCIAS}

ABERASTURY, A.; SALAS, E. J. A paternidade: um enfoque psicanalítico. Porto Alegre: Artes Médicas, 1991.

ARIÈS, P. História social da criança e da família. 2. ed. Rio de Janeiro: LTC, 1981.

ARILHA, M.; MEDRADO, B.; RIDENTI, S. Introdução. In: ARILHA, M.; RIDENTI, S.; MEDRADO, B. (Org.). Homens e masculinidades: outras palavras. São Paulo: 34, 1998, p. 15-84.

BARBOSA, M. C. S. Fragmentos sobre a rotinização da infância. Educação $e$ Realidade, Porto Alegre, v. 25, n. 1, p. 93-113, jan./jun. 2000.

CALligARIS, C. Crônicas do individualismo cotidiano. São Paulo: Ática, 1996.

CASTRO, L. R. A infância como alegoria. Arquivos Brasileiros de Psicologia, Rio de Janeiro, v. 50, n. 3, p. 5-13, jul./set. 1998. 
CORAZZA, S. Era uma vez... Quer que conte outra vez? As gentes pequenas e o indivíduo. In: GARCIA, R. L. (Org.). Crianças, essas conhecidas tão desconhecidas. Rio de Janeiro: DP\&A, 2002, p. 31-52.

COSTA, G. P. Conflitos da vida real. Porto Alegre: Artes Médicas, 1997.

COSTA, J. F. Ordem médica e norma familiar. 4. ed. Rio de Janeiro: Graal, 1999.

DOR, J. O pai e sua função em psicanálise. Rio de Janeiro: J. Zahar, 1991.

É TÃO importante como a mãe. Correio do Povo, Porto Alegre, p. 8, 12 ago. 2001.

FISCHER, R. M. B. O estatuto pedagógico da mídia: questões de análise. Educação e Realidade, Porto Alegre, v. 22, n.2, p. 59-77, jul./dez. 1997.

FOUCAULT, M. História da sexualidade 1: a vontade de saber. 13.ed. Rio de Janeiro: Graal, 1999.

FOUCAULT, M. A arqueologia do saber. 6.ed. Rio de Janeiro: Forense Universitária, 2000a.

FOUCAULT, M. Microfísica do poder. 12. ed. Rio de Janeiro: Graal, 2000b.

GÉLIS, J. A individualização da criança. In: CHARTIER, R; FEIST, H. (Org.). História de vida privada 3: da renascença ao século das luzes. São Paulo: Cia das Letras, 1991, p. 311-330.

GIDDENS, A. Mundo em descontrole. Rio de Janeiro: Record, 2000.

HENNIGEN, I. A paternidade na mídia contemporânea: discursos e modos de subjetivação. 2004. Tese (Doutorado)-Pontifícia Universidade Católica do Rio Grande do Sul, Porto Alegre, 2004.

HENNIGEN, I.. Os discursos das disciplinas PSI sobre o pai. In: GUARESCHI, N. M. F.; HÜNING, S. M. (Org.). Implicações da psicologia no contemporâneo. Porto Alegre: EDIPUCRS, 2007, p. 103-134.

KNIBIEHLER, Y. Padres, patriarcado, paternidad. In: TUBERT, S. (Org.). Figuras del padre. Madrid: Cátedra, 1997, p. 117-135.

MULHERES apaixonadas. Direção: Ricardo Waddington. Escrita por: Manoel Carlos. Intérpretes: Christiane Torloni, José Mayer, Tony Ramos, Susana Vieira, Helena Ranaldi, Giulia Gam, Marcello Antony e outros. Produzida por Central 
Globo de Produções, 2003. Telenovela, son., color. 203 episódios.

MUZIO, P. Paternidade (ser pai)... Para que serve? In: SILVEIRA, P. (Org.) Exercício da paternidade. Porto Alegre: Artes Médicas, 1998, p. 165-174.

COMERCIAL das Lojas Renner. Produção: Paim Comunicação. Porto Alegre, 2000.

PERROT, M. Figuras e papéis. In: . História da vida privada, 4: da revolução francesa à $1^{\mathrm{a}}$ guerra. São Paulo: Cia das Letras, 1991a, p. 121-185.

PERROT, M. Funções da família. In: História da vida privada, 4: da revolução francesa à $1^{\mathrm{a}}$ guerra. São Paulo: Cia das Letras, 1991b, p. 105-119.

RAMIRES, V. R. O exercício da paternidade hoje. Rio de Janeiro: Rosa dos Tempos, 1997.

ROSE, N. Governando a alma: a formação do eu privado. In: SILVA, T. T. (Org.). Liberdades reguladas: a pedagogia construtivista e outras formas de governo do eu. Petrópolis: Vozes, 1998, p. 30-45.

SILVA, T. T. As pedagogias psi e o governo do eu nos regimes neoliberais. In: . Liberdades reguladas: a pedagogia construtivista e outras formas de governo do eu. Petrópolis: Vozes, 1998, p. 7-13.

SILVEIRA, P. O exercício da paternidade. In paternidade. Porto Alegre: Artes Médicas, 1998, p. 27-39.

. (Org.). Exercício da

Recebido em: julho de 2008

Aceito em: março de 2010 
